\title{
Computability, Complexity and Randomness
}

\section{Rod Downey}

Published online: 5 October 2012

(C) Springer Science+Business Media New York 2012

This special issue of Theory or Computing Systems consists of papers associated with the 6th Annual CCR conference held in beautiful Cape Town, 31st JanuaryFebruary 4th 2011. The conference series is devoted to issues around algorithmic information theory, Kolmogorov complexity, and their relationship with computability theory, complexity theory, logic and reverse mathematics. In 2011, the conference was co-located with the 8th Annual Computability and Analysis conference. This co-location reflects the increasing interactions between computable analysis and algorithmic randomness through effective analysis of almost everywhere behavior in analysis such as the Lebesgue Differentiation Theorem and things like Brownian motion. Both conferences were admirably overseen by Vasco Brattka and his program committees.

The last 10-15 years has seen huge progress in the areas represented by CCR with two long monographs in the area, recognition at the International Congress of Mathematicians, and a thoroughly thriving research community.

Whilst the CCR conference uses a model which does not have an actual proceedings at the meeting, the papers in this special issue reflect the meeting's business. These papers reflect the high caliber of both the researchers and the intellectual merit of the investigations. The work spans issues from applications in biology, computer science to fundamental issues about Kolmogorov complexity. The papers all went through the full Theory of Computing Systems journal reviewing process and several of the initial submissions were rejected. Enjoy.

R. Downey $(\bowtie)$

School of Mathematics, Statistics, and Operations Research, Victoria University, Wellington, New Zealand

e-mail: rod.downey@vuw.ac.nz 